\title{
Study on High Quality Farmland Demarcation
}

\author{
Mei Shan ${ }^{1,2,3, a}$, Jing Wang ${ }^{3, b}$ \\ ${ }^{1}$ College of Resources and Environment, \\ Shandong Agricultural University, \\ Taian 271018, China \\ ${ }^{2}$ Department of Tourism, Taishan University, \\ Taian 271021, China \\ ${ }^{3}$ Key Laboratory of Land Use, Ministry of Land and Resources, \\ China Land Surveying \& Planning Institute, \\ Beijing 100035,China \\ aemail: tigertaishan@163.com \\ bemail: wangjing@mail.clspi.org.cn
}

\begin{abstract}
The article aiming at the problems of current domestic quality of farmland, expounded the status of China's farmland resources, the necessity and feasibility to delineate high quality farmland, put forward the concept and characteristics, determine links and protection measures of high quality farmland, finally raised some suggestions about how to the demarcate high quality farmland.
\end{abstract}

Keywords-high quality farmland; quality of farmland; farmland protection

\section{INTRODUCTION}

Farmland is the essence of land, it is the basis material for agricultural production , and it is hunam's lifeline. According to estimates, more than $80 \%$ of the calories and more than $75 \%$ protein, $88 \%$ food to prop up human life come from farmland ${ }^{[1]}$. The problem of farmland is related with our country's food security, ecological environmental quality, social stability and state power's rise and fall, its strategic position has become increasingly important.

More population, less farmland is China's basic national conditions, the problem is difficult to change in a long period of time. Since the reform and opening up, Especially since 1990s, with the increase of population and the improvement of people's living standard, the farmland resources in China faces enormous pressure and severe situation ${ }^{[2]}$. On the one hand, with the process of industrialization, city to the occupation of farmland and the pressure of structural adjustment, the farmland is reducing speed ${ }^{[3]}$; On the other hand, a lot of high quality farmland have been non-agricultural land expropriation, especially in the economy more developed regions, construction takes up much of high quality farmland ${ }^{[4]}$. With plenty of manure, fertilizer and pesticide industry predatory long-term, resulting in the quality of farmland decreased continuously ${ }^{[5]}$. Land issue has more and more attracted national attention.

\section{CURRENT SITUATION OF THE FARMLAND RESOURCES IN CHINA}

\section{A. The Number of Existing Arable Land of China}

China's per capita arable land is only $1.38 \mathrm{mu}$, about $40 \%$ of the world average level, part of southeast coastal region's average per person farming is lower than the UN Food and agriculture organization determined $0.053 \mathrm{hm}^{2}$ warning line. That the Ministry of land and resources statistics,from 1998 to 2008, supplementary farmland quantity less than a reduction in the number, a net decline of 1.193 billion mu (Figure 1). The current cultivated land area of about 1.826 billion mu, closer to the red line of 1.8 billion mu . Mounting pressure of the cultivated land protection. Although China attached great importance to the protection of arable land, taked a variety of legal, administrative, economic, technological and other measures to protect farmland number, quality and ecological environment, but bue to long-term extensive land formed by the use of free of charge, led to the decrease of the land, especially the farmland quantity decrease year after year, and soil erosion, land desertification, soil degradation, serious problems such as "three wastes" pollution especially serious.

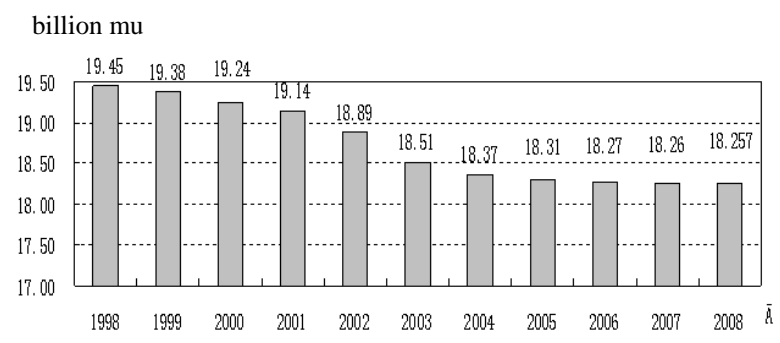

Figure 1. The Interannual variation of farmland in China during 1998-2008

The Ministry of land and resources data published in the bulletin of the Ministry of land and resources 


\section{B. Existing Farmland Quality}

Poor quality of cultivated land distribution is not uniform, and the reason is affected by water, heat, gas, topography and other conditions of the restrictions, coupled with the impact of factors such as all kinds of pollution. In 2009 December, the Ministry of land and resources of the People's Replic of China released " Study on Investigation and Assessment of Cultivated Land Quality Grade in China ", the farmland be categorized into 15 quality grades in China, 1grade was the best quality and 15 grade was the worst. Not less than 10 million hectares of $7-13$ grade farmland area of accounted for $78.10 \%$ of the total area of the farmland evaluation area ${ }^{[6]}$ (Figure 2).

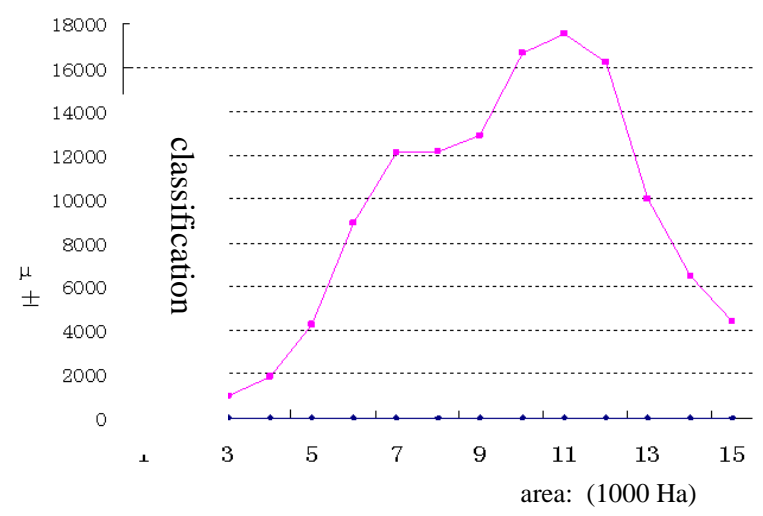

Figure 2. Level area of farmland in China

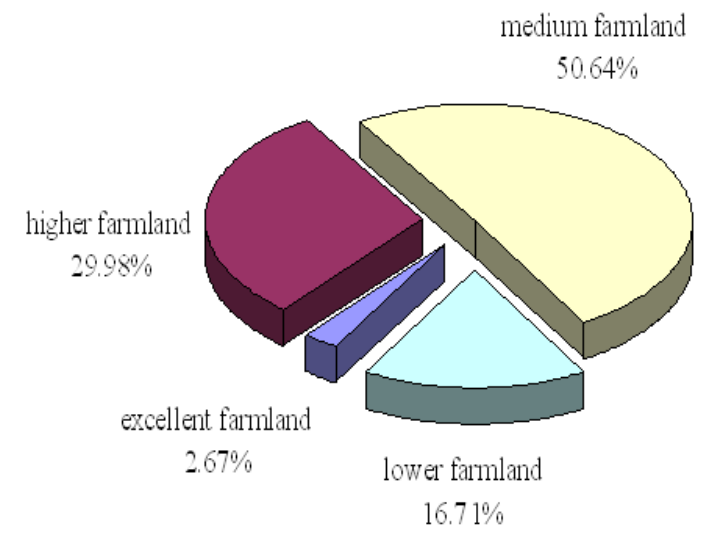

Figure 3. constitute of area and ratio for excellent, higher, medium, inferior grade farmland in China

The farmland in accordance with the 1-4, 5-8, 9-12, 13-15 grades were divided into superior, medium and lower level. Among them, superior area of 3337560 hectares, accounting for $2.67 \%$ of the total area of farmland evaluation; higher to 37509490 hectares, accounting for 29.98\%; medium to 63360620 hectares, accounting for $50.64 \%$; low to 20907390 hectares, accounting for $16.71 \%$ (Figure 3).

The distribution of farmland in China, significant geographical differences, mainly distributed in the southeast of humid and semi humid monsoon region, the optimal overall top three is the Yangtze Rive $\mathrm{r}$ area, Southern China District, Jiangnan District, the average quality grades were $6.37,7.07$ and 8.18 etc. The overall worst after three is the Loess Plateau, the Qinghai Tibet plateau area and Inner Mongolia plateau and along the Great Wall area, he average quality grades were 11.84 , 12.17 and 13.39 etc.

To ensure food security, by storing food in land especially the quality of farmland. But in reality, the number and quality of farmland in China is not optimistic. Rapid development of industrialization, urbanization, inevitably to occupy a lot of farmland. The national soil and water and heat conditions are better quality of farmland, mainly distributed in the southeastern area, and these areas are currently the non-agricultural construction covering up, the fastest, the"land flowing with milk and honey" scene in some places have a rare. The existing farmland in China, according to statistics, reduction of farmland soil and water loss is 45300000 hectares farmland, reduction of farmland salinization is 8000000 $\mathrm{hm} 2$, reduction of farmland desertification is 2700000 $\mathrm{hm} 2$, desertification, reduction of farmland by industrial wastes (waste water, waste gas,waste residue) is 6000000 $\mathrm{hm} 2$, the harm of acid rain is $2700000 \mathrm{hm} 2$; the farmland pollution and degradation in China is serious. The results show in the eastern province of contaminated soil area was nearly ninety percent ${ }^{[7]}$. Every year,because of water loss and soil erosion, soil salinity and land desertification, the loss of farmland is still on the rise every year in China.

\section{Reserve Land Resources}

According to the survey, the land suitable for agriculture reserve resources area is 44.24 million hectares, Land suitable for farming reserve resources area is 9.88 million hectares. Development of supplementary farmland area is 5.8667 million hectares, accounting for the total potential of farmland supplement $44 \%$. At present, more than $60 \%$ arable land reserve resources distribution in water shortage, water and soil erosion, desertification and salinization in northwest area, many restricting factors for the development of utilization, developed mostly low, if the improper development. The restriction of land development and utilization of many factors, developed land is most lower level of farmland, if inappropriate development, also can cause ecological environment problems, development and utilization is very difficult. So cause shortage of arable land reserve resources.

\section{NECESSITY OF HIGH QUALITY FARMLAND DEMARCATION}

The change of the farmland quality is a serious threat to the ecological environment and the development of social economy ${ }^{[8]}$. For a long time, the quality of cultivated land protection is always the hot social issues. The Party Central Committee, the State Council attached great importance to the quality of farmland protection, "Land Management Law" stipulates the use of farmland compensation system, keep a balance in mumber and quality between farmland occupied and farmland developed and reclaimed ${ }^{[9]}$. But in 
practice, high level of farmland loss too fast, supplement of farmland is mainly distributed in hydrothermal, location, terrain conditions are relatively poor areas, the overall quality is not high, the quality level is low, shoddy situation is very serious, the overall quality of farmland decreased, has seriously affected the production capacity of arable land in China and threat to national food security. In this sense, only to keep1800000000 acres of farmland quantity is not enough, must need to ensure the quality .the steady improvement in the productive capacity of farmland. Close attention is paid to the decline of farmland quality problems ${ }^{[6,10-11]}$.

The farmland quality, not only affects the crop yield, but also has a direct impact on the quality of agricultural products. After the reform and opening up, despite the decrease of farmland area, but because of the increase of soil fertility quality of farmland, agricultural output increased greatly, so that China use $22 \%$ of the world's population is fed on $7 \%$ of the world's farmland, created the world wonders. However, with the increasing number of population growth and demand for agricultural products is increasing, people's living standard and China's accession to the WTO after the acceleration of global economic integration, the agricultural products harmless and good nutrition of the increasingly high demand, agricultural products harmless and good nutrition has become an important index to reflect the ability of competition the agricultural product market and international market access. And the high quality farmland is not only the foundation of agricultural sustainable development,bus is the basic guarantee for agricultural products harmless and good nutrition. In order to enhance the production capacity of farmland, to optimize the quality of agricultural products, the urgent need for high quality farmland demarcation.

Analysis of the factors affecting the quality of farmland is often too much to consider natural factors, especially soil fertility, while too little concern on social economy, ecological environment factors. How to all aspects of the evaluation index organically worth exploring ${ }^{[12]}$. By delineating the high quality farmland, use natural, social, economic, policy and ecological factors combined to conduct a comprehensive assessment of the quality of farmland, will provide a reference for the transformation of land resources in China from quantity management to quality and ecology protection.

\section{FEASIBILITY OF HIGH QUALITY FARMLAND DEMARCATION}

The current domestic and foreign scholars have conducted extensive research on the quality of farmland resources management departments. Different resource management department, due to their different management scope, purpose and focus on the quality evaluation of farmland is not consistent. China's industry standard for cultivated land quality evaluation at present is mainly formulated by agricultural department and the administrative department of land and resources. In 2000 the Ministry of Agriculture issued "Green food-Technical conditions for environmental of area ", provides the green food producing area environmental air quality, the irrigation water quality, water quality, livestock water quality and soil environment quality indicators and concentration limits, monitoring and evaluation method; in 2003 the Ministry of agriculture to develop the " Classification of type regions and fertility of cultivated land in China " industry standard ${ }^{[13]}$, combined with conventional grain yield per unit area and soil fertility factor condition divided the country into 7 types of farmland area, 10 of farmland fertility grading. First class farmland is the highest yield, ten class farmland is the lowest yield [14]; the Ministry of agriculture in 2008 formulated" Rules for soil quality survey and assessment ", established a method, investigation and evaluation of soil fertility and environmental quality of farmland in farmland program and content, the environmental quality of farmland is defined in the soil heavy metal pollution, pesticides and irrigation water quality ${ }^{[15]}$; in 2009 the Ministry of land and resources issued "China's cultivated land quality level investigation and evaluation", but not consider soil pollution factors in the evaluation of farmland quality. In addition, water conservancy, forestry, environmental protection and other relevant departments also has the similar standard about farmland. All of these standards provide the basic data for high quality farmland demarcation

\section{HIGH QUALITY FARMLAND DEMARCATION}

\section{A. Concept of High Quality Farmland}

The high quality farmland is the function of the national food security. The high quality farmland security is the development of population and social economy in a certain period of time the demand for food, not only to solve the problem of food and regional population, but more important is to ensure the national demand for commodity grains.

High quality farmland quality is guaranteed harvest, high yield and no pollution. The high quality farmland play a major role in the protection of national food security, it must be cultivated land in agricultural facilities is best, the most fertile soil, the strongest resistance against natural disasters, minimal pollution, and is the farmland main production of grain crops.

Protection of high quality farmland must take measures of rigor and long-term timeliness. The high quality farmland is the best part of the farmland, should be long-term use and can not reduce, not only be adjusted, the area can only increased, and the quality can only be improved.

Therefore, the concept of high quality farmland set: high quality farmland including the existing and potential high quality farmland land. Refers to the farmland has the superior natural conditions, agriculture supporting facilities, fertile soil, soil quality, crop high yield, crop quality high, drought or wate rlogging, high and stable yield, represents an area the highest level of natural productivity, to ensure food safety of great significance. 
The high quality farmland has characteristics as number of small, high yield, crop quality high, easy to be take, difficult to compensation.

\section{B. Delineation of High Quality Farmland and Protection}

If the concept of high quality farmland was established above, high quality farmland is premise so designated by some evaluation methods to separate the high quality farmland from the land. Therefore, the protection of farmland should include such steps as rating level, land division, data establish and system perfect.

a) Evaluation of Farmland Quality Grade

To comprehensive assessment of a certain region ,including factors as farmland fertility, the ecological environment, water environment, the input and output efficiency. According to China has farmland quality grade evaluation and soil pollution investigation, in accordance with the concept of high quality farmland, the area of arable land grading, the deep soil, moderate texture, soil fertility quality, improve irrigation and drainage facilities, Drought or flood when food is a good harvest, field structured, concentrated, multiple cropping index reached more than $100 \%$, higher yield, maintain a good ecological environment, nopollution to the ecological environment of farmland priority designated as high quality farmland.

\section{b) Delineation of High Quality Farmland Division}

On the basis of farmland grade appraisal result, considering the economic and social development planning, delineation of high quality farmland. The high quality farmland demarcation principles to the original protection of land division, can also according to the actual situation and different levels of standards appropriate apart and in pieces, break through the boundaries of administrative villages. For non-agricultural construction land planning period basic not occupy, suitable for the cultivation of food crops, relatively centralized management right of farmland and the implementation of high yield farmland construction, agricultural land development projects, agricultural scientific research and teaching experimental plot, priority designated as high quality farmland.

c) Implement the Protection of High Quality Farmland

To place a strict control on the usages of high quality farmland. First advocate the farmers grow rice, wheat, rape and other food crops in the high quality farmland designated zone. After relevant supporting policies announced, such as Regulations on the Protection of Basic Farmland, then can achieve high quality farmland use control on real significanc. appointe certain persons to protect the high quality farmland; further improve the farmland protection system, the county has a leading group, the township has protection program, each village has wardens, group has the messenger, every household has a duty to understand card. At the same time, the protection of high quality farmland, be like " forest ranger ", in the town as a unit to hire the 2-3 of high quality cultivated land protection specialist.
Intensify the construction of high quality farmland. In high quality cultivated land relatively concentrated area vigorously promote the construction of high-yield field and strive to further improve agricultural infrastructure, improve the quality of farmland, to get high quality farmland sustainable use.

To implement high quality farmland protection funds. At practical work, the farmland protection funds for construction more, for the protection less. List the high quality farmland protection funds in accordance with per mu each year a certain standard after the quality farmland are defined, special use funds to basic day to day operation, network protection, dynamic inspection of high quality framland.

\section{DELINEATION OF HIGH QUALITY FARMLAND}

\section{A. Overall Planning, Rational Distribution}

The high quality farmland is the most basic food safety in China, in the scope and proportion should take the overall or by the province as a unit to co-ordinate arrangements, prominent concentrated, delimit the focus in major grain producing areas.

\section{B. Establishment of Compensation Mechanism for the Protection, Using the Economic Levers to Regulate the Positive Protection Farmland}

Grain production benefit is low, leading to the enthusiasm of local governments and farmers in grain production is not high. We should formulate specific measures to implement as soon as possible compensation mechanism of farmland protection. Extraction of compensation money from the local finance income. In the compensation allocation of funds, according to the high quality farmland area, grain production in many factors to distribution. On the one hand, subsidies compensation funds to grain farmers and local government, change the passive situation"more grain-growing and more poor, better land protection and difficult to develop". On the other hand, strengthen the protection and construction of facilities management and investment funds, to ensure that the total amount of farmland is not reduced, designated uses does not change, the quality has been improved.

\section{Strengthen the Protection Measures, Ensure High Quality Farmland Will not be Permanently Damaged}

In view of the high quality farmland protection, enforcement agencies recommended the establishment of land and resources law enforcement, establish police station of land and resources in the county, ensure timely and effectively combat the destruction of farmland and other illegal acts.

Designate a certain amount of high quality farmland and permanent protection, can ensure the country have a more stable food production capacity, to ensure the food supply for production capacity and food security. But the high quality farmland in China has not the clear conception and formulationis, yet has no specific standard for the delineation of high quality farmland. Along with the 
implementation of the 12th Five Year Plan, delimit the high quality farmland will become a new way for farmland protection.

\section{REFERENCES}

[1] Feng Zhiming. To Set Up China's Cultivated Land Preserves, Science and Technology Review, 1993(1) : 42-43,20

[2] Wu Yu-ming. Non-linear Fractional R/S Trend Analysis of the China's Population Evolution [J]. China population science,2005(4):48-53,96

[3] Liu Jinghui, Wang Zhiming Li lijun. Macroscopic Analysis on Resources Consumption of Grain Production in China [J]. Review of China Agricultural Science and Technology,2004,6(4):22-27

[4] Chen Baiming. Situation and Counter Measures For Protection Of Arable Land and Basic Farm Lands. Chinese of Agricultural Resources and Regional Planning. 2004,25(5):1-4.

[5] Ma Qingxin, He Sanlin. The current rural farmland abandoned and decline in the quality question discussion [J]. Journal of China Agricultural Resources and Regional Planning ,2002,23(4):19-21.

[6] Ministry of Land and Resources of the People's Replic of China. Study on Investigation and Assessment of Cultivated Land Quality Grade in China [S] : December 2009

[7] Song Wei, Chen Baiming,Liu Lin. Soil Heavy Metal Pollution of Cultivated Land in China [J] .Research of Soil and Water Conservation, 2013, 20 (2) : 293-298.
[8] Ni Shaoxiang, Liu Yansui. Try To Talk About the Importance Of the Quality of Cultivated Land in Total Arable Land Dynamic Balance [J]. Economic Geography, 1998, 19 (2) : 83-85.

[9] HuaYuanchui. Reflection on Quantity and Quality Equilibrium of Cultivated Land[J]. Scientific and Technological Management of Land and Resources,2006, 23(2) :1-4

[10] Zhong Yu, Qin Fu. "Hidden Grain Among the People" to "Storing Grain In the Land" -- the Experience of the Exploration to Improve the Quality of Cultivated Land Protection In Hunan Province and the Existing Problems [J]. Heilongjiang Grain. 2009, 1:31-32.

[11] Sun Youhai ,Chai Taoxiu. In the New Historical Starting Point to Strengthen the Quality of Cultivated Land Protection [J]. China Land, 2009(1) :34 -38.

[12] NieYan. Researchon Models, Methods and Information System Integration and Application of Cropland Quality Evaluation [D]. Wuhan: Huazhong Agricultural University, 2005.

[13] Zheng Zhaopei, Liu Zuoxin. Soil quality and its evaluation[J]. CHINESE JOURNAL OF APPLIED ECOLOGY, 2003,14(1) : 131-133.

[14] Ministry of Agriculture of the People's Republic of China. Classification of type regions and fertility of cultivated land in China [S], Dec 1996.

[15] Ministry of Agriculture of the People's Republic of China.Rules for soil quality survey and assessment, June 2008. 